\title{
Oral and Skin Lesions Among Yemeni Khat Abusers While Chewing and After Quitting®Crosse-Sectional Survey
}

\section{Rowida A. Albarmaqi}

Kunming Medical University First Affilliated Hospital https://orcid.org/0000-0003-3089-2057

Yi-Qun Kuang ( $\sim$ yq610433@hotmail.com )

https://orcid.org/0000-0002-1452-4388

\section{Yu-Ye Li}

Kunming Medical University First Affilliated Hospital

\section{Noha Saleh Gholais}

Lanzhou University

\section{Research}

Keywords: Catha edulis, Ex-chewer, Khat abuser, Oral health, Skin.

Posted Date: September 27th, 2021

DOI: https://doi.org/10.21203/rs.3.rs-895754/v1

License: (c) (i) This work is licensed under a Creative Commons Attribution 4.0 International License. Read Full License 


\section{ABSTRACT}

Background: Khat chewing is a routine practice in Yemen. Associations between Khat chewing and various adverse oral-dental health conditions have been recorded, however, adverse skin health evidence is still lacking.

Objective: To investigate the difference between oral and skin symptoms and signs while chewing Khat and after quitting chewing among Yemeni khat abusers.

Method: A descriptive cross-sectional study was conducted on a sample of 300 Yemeni Khat ex-chewer participants in china. Khat chewing status data, a range of oral and skin symptoms and signs, and other pertinent variables were collected using self-administered questionnaires by WeChat. The mean differences between oral and skin symptoms and signs while chewing Khat and after quitting chewing were investigated using the Paired Samples t-test.

Result: Of the 300 Yemeni who participated in the study, 255(85\%) were men and 45(15\%) were women. The oral symptoms and signs mean while chewing was $0.26,0.022$ (standard deviation [SD], whereas that after quitting chewing Khat was 0.10 (mean), 0.269 (standard deviation [SD], $t$ (12.00), $\mathrm{P}=0.00$. The skin symptoms and signs mean while chewing was $0.13,0.28$ (standard deviation [SD], whereas that after quitting chewing Khat was $\mathrm{M}=0.06,0.21$ (standard deviation [SD], $\mathrm{t}(9.407), \mathrm{P}=0.00$.

Conclusions: There is a statistically significant difference between the mean oral and skin symptoms and signs while chewing and after quitting, whereas long-term Khat chewing negatively affects oral and skin health.

KEYWORDS: Catha edulis, Ex-chewer, Khat abuser, Oral health, Skin. 


\section{INTRODUCTION}

The qat or Khat (Catha edulis) is an evergreen plant that belongs to the Celastraceae family. This tree is grown in Yemen and some countries of East Africa including Ethiopia, Kenya, Tanzania, Somalia, and Madagascar [1, 2]. The young buds and fresh tender khat leaves are traditionally chewed to achieve a state of euphoria and relaxation due to their amphetamine-like effect [1]. Khat chewing affects the dopamine neurotransmitters causing high levels of dopamine to feed the synapse giving off its typical euphoric effect [2]. Cathinone, an amphetamine-like sympathomimetic amine, and Cathine are the most active psychoactive components of Khat [2]. Khat chewing is a deeply ingrained tradition in Yemen, and recent epidemiological reports suggest that more than $70 \%$ of males and $30 \%$ of females are Khat users on a regular basis $[1,3]$.

Several studies have reported a variety of Khat-related oral and dental diseases, including gingivitis, periodontitis, dental discoloration and attrition, temporomandibular junction disorders, mucosal pigmentation, xerostomia, stomatitis of plasma cells, and keratotic lesions [4-8]. Other mucosal changes associated with Khat chewing have also been reported to include ulcers, hairy tongue and reactive benign swelling cells, and keratotic lesions $[4,5]$. Besides, the frequent and prolonged period of Khat chewing had a positive correlation with the incidence and severity of keratotic lesions, independent of smoking status [9, 10]. Common knowledge that among Khat chewer, the periodontal health status is better than non-chewer [11] or in the chewing side of the mouth compared to the chewing side [12]. Gorsky et al. [13] report that on Yemeni Jewish qat chewers could not find any malignant or premalignant lesions. Similarly, in another study in Kenya among the Ameru people, a correlation between Khat chewing and leukoplakia was not identified [14]. In fact, some researches failed to identify any positive correlation between Khat and precancerous or oral cancer lesions $[9,13,15]$. There is still poor proof that chewing Khat is risk 
factors for oral tumors, and is based primarily on uncontrolled research and anecdotal case reports.

Furthermore, methamphetamine's (drug abuse) studies been reported some skin manifestations, including hyperhidrosis, foul body odor, dry skin (xerosis), lipodystrophy, premature aging, infections secondary to formication, and acne excoriate [16]. Poor oral hygiene, dental caries, xerostomia, and bruxism contribute to severe dental decay [17].

Most previous work has only focused on the correlation between Khat chewing and the prevalence of oral diseases. However, there are no previous studies had been established whether Khat chewing could affect skin health.

Hence, the present study calls into question whether there is a difference between the oral and skin symptoms and signs while Khat chewing and after quitting.

\section{Materials and methods}

A cross-sectional study was conducted among Yemeni Khat ex-chewers who are living in China, and using WeChat application. Because we also had a plan to investigate the difference between oral and skin symptoms and signs while Khat chewing and after quitting, we restricted the sample population to only Yemeni Khat ex-chewers who were in China.

All the Yemeni citizens who used to chew Khat, age more than 15, living in China, and have WeChat account were included in this study. However, the ex-chewers or non-chewers who are not in China were excluded.

\section{Data collection}

Ethical clearance and permission was obtained from Kunming first affiliated Hospital and Kunming Medical University. The data collection was carried out using an online questionnaire which was pretested. Potential participants were invited through a text message on WeChat Yemeni Groups, which connected them to a survey page. Data was collected anonymously, with no 
information that could be used to identify the participants. An Arabic-edition of the questionnaire was primarily used. The period of data collection was between $17^{\text {th }}$ and $21^{\text {th }}$ October 2020.

\section{Study questionnaire}

Once the participants clicked on the link in their Wechat account they were provided information about the nature and purpose of survey on the first page. Subsequently, if they consented to participate, they were taken to next page. The questionnaire contained items to assess oral and skin symptoms and signs while chewing and after quitting chewing and other relevant variables. The study variables included socio-demographic variables such as sex, age, educational level, and occupation. Additional important variables included information on Khat chewing status, length of stay in China, smoking cigarettes, smoke water pipe, having systemic disease, and family members of participants who chew Khat, withdrawal symptoms after quitting and duration. It also contained ten items about oral symptoms and signs such as difficulty chewing food (pain), mouth sores/irritation, mouth angular fissure, mouth white spots, oral malodor, gum bleeding, change the colour of the tongue, tongue fissure, tongue bumps or lump oral and raised bumps that are white or red. These items were adapted from the Locker and Mille research [18]. It also contained twelve items about skin symptoms and signs such as skin rash, feeling itchy, dry skin, rough skin texture, peeling skin, abscess, dark velvety skin patches or spot, hyperhidrosis, foul body order, cold sore oral herpes, purpura, noticeable loss of glowing complexion of the face with dark circles or facial fine line and had herpes zoster.

\section{Statistical analysis}

All data were entered twice using the SPSS software version 23 to facilitate the detection of data-entry errors. For demographic data, frequencies and percentages were reported using 
descriptive statistics. To identify whether there is a difference between oral and skin symptoms and signs, while chewing Khat, and after quitting chewing among Yemeni ex-chewers, a paired-samples t-test was used.

\section{RESULT}

\section{Socio-demographic characteristics}

Of the 300 subjects who participated in the study, 255 (85\%) were men, congruent with the proportionally large male veteran population, and $45(15 \%)$ were women. The majority of the respondents $269(89.6 \%)$ were less than 35 years. All of the participants were Khat Yemeni ex-chewers in China only. $83(27.7 \%)$ cigarette smokers and 119 (39.7\%) water-pipe smoke. The majority of the subjects $218(72.7 \%)$ were students, $119(39.9 \%)$ were bachelor's degree. 153(51\%) were postgraduate degree. A total of 48 (16\%) participant have been in China for one year, 65 $(21.7 \%)$ for $2-4$ years, $130(43.3 \%)$ for $5-7$ years, $57(19 \%)$ more than eight years. $6(2 \%)$ participants have the systemic disease as (DM, hypertension, asthma, rheumatic, gout). However, 273 (91\%) have a family member who chews Khat, 27 (9\%). The Socio-demographic characteristics are listed in Table 1.

\section{Chewing Khat status}

The descriptive analysis of the data regarding the chewing Khat status and other basic information has summarized below in Table 2. 121 (40.3\%) of participants chewed Khat for less than or equal to 3 years, $100(33.3 \%)$ for 4-7years, $45(15 \%)$ for 8-11 years, $16(5.3 \%)$ for 12-15 years, and $18(6 \%)$ chewed more than 16 years .108 (36\%) chewed for 1-3 hours per a day, 123 (41\%) for 4-6 hours per a day, 50 (16.7\%) for 7-9 hours per a day, and 19 (6.3\%) chewed Khat for 
more than 10 hours per day. The amount of chewed Khat by bundles among the participants was, a quarter in $103(34.3 \%)$, Half a bundle in $60(20 \%)$, one bundle in 101 (33.7\%), more than one bundle in $36(12 \%)$.

\section{Withdrawal symptoms and duration}

When the participants were asked about withdrawal symptoms after quitting chewing Khat. The majority of the respondents $132(44 \%)$ felt the craving and $121(40.3 \%)$ felt increased appetite or hungry all of the time. However, 69 (23\%) felt depression, 47 (19\%) felt irritability, 77 (25.7) felt Tiredness and restlessness, $111(37 \%)$ sleeping longer. The participants could have one or more symptoms. However, $224(74.7 \%)$ of participants took less than seven weeks to come over the withdrawal symptoms, $24(8 \%)$ took 8-13 days, 52 (17.3) took more than 14 days. Fig. 1 and Table 3 show the withdrawal symptoms after quitting chewing and the duration it takes.

\section{Proportion of oral and skin symptoms and signs}

In response to oral and skin symptoms and signs while chewing Khat and after quitting chewing questions, questions reported more frequency of oral and skin symptoms and signs while the participants were actively chewing compared to after quitting chewing Khat. In details, the oral symptoms and signs included difficulty-chewing food (pain) in 83 (10.7\%), Mouth sores/irritation in $91(11.7 \%)$, Mouth angular fissure in $94(12.1 \%)$, mouth white spots in $61(7.9 \%)$, oral malodor in $76(8.6 \%)$, gum bleeding in $80(10.3 \%)$, change the color of tongue in $123(15.8 \%)$, tongue fissure in $68(8.8 \%)$, tongue bumps or lump oral in $62(8.0 \%)$, raised bumps that are white or red in $48(6.2 \%)$. Table 4 compares the frequencies of oral symptoms and signs while chewing Khat and after quitting chewing. The skin symptoms and signs questions reported that skin rash in 19 (1.9\%), feeling itchy in $29(2.9 \%)$, dry skin rough skin texture in $56(5.5 \%)$, peeling skin in $37(3.6 \%)$, 
abscess in $28(2.8 \%)$, dark velvety skin patches or spot in $27(2.7 \%)$, hyperhidrosis in $74(7.4 \%)$, foul body order in $37(3.7 \%)$, cold sore oral herpes in 29 (2.9\%), purpura in 20 ( $2.0 \%)$, noticeable loss of glowing complexing of the face with dark circles or facial fine line in $106(10.4 \%)$, and having herpes zoster while chewing in $17(1.7 \%)$ and $10(1.0 \%)$ after quitting chewing. Details of the skin symptoms and signs by Khat chewing status are listed in Table 5.

\section{The means differences of oral and skin lesions while chewing and after quitting chewing in}

\section{Khat abusers.}

The mean differences of oral and skin symptoms and signs while chewing and after quitting chewing were assessed using the paired sample t-test, (A paired sample t-test was conducted to compare the means of oral and skin signs and symptoms while chewing Khat and after quitting chewing Khat), which have detailed below in Table 6. According to this analysis, There was a significant difference in the oral signs and symptoms while chewing $\mathrm{M}=0.26, \mathrm{SD}=0.022$, and after quitting chewing Khat was $\mathrm{M}=0.10, \mathrm{SD}=0.269$. $\mathrm{t}$ (12.00) , $\mathrm{p}=0.000$. There was a significant difference in the skin signs and symptoms while chewing $\mathrm{M}=0.13, \mathrm{SD}=0.28$, and after quitting chewing Khat was $\mathrm{M}=0.06, \mathrm{SD}=0.21, \mathrm{t}(9.407), \mathrm{p}=0.000$.

\section{DISCUSSION}

This study was designed to investigate whether there is a difference between oral and skin symptoms and signs while chewing Khat and after quitting chewing Khat among Yemeni abusers in China. The major findings of our study were:

(1) The withdrawal symptoms among the participants after quitting chewing in $69(23 \%)$ of participants felt mild depression, Irritability in 57 (19\%), craving in 132 (44\%), Tiredness and restlessness in $77(25.7 \%)$. Moreover, increased appetite/feeling hungry all of the time in 121 
(40.3\%), sleeping longer in 111 (37\%). The findings of the present study support a previous study, which been reported that during Khat withdrawal, after prolonged khat use, consisting of lethargy, mild depression, slight trembling, and possibly recurrent bad dreams may occur $[19,20]$. In 1980 WHO had classified Khat as a drug of abuse that could induce psychological dependence [21]. The most active psychoactive ingredients of Khat are Cathinone, an amphetamine-like sympathomimetic amine, and Cathine. However, Cathinone is several times stronger than Cathine and is therefore designated a schedule I drug (most restricted and harmful type), whilst Cathine is a schedule Ill type drug (less potential for abuse and has acceptable use in certain areas of medicine) in the USA [22]. Although the WHO does not consider Khat addiction to be a serious problem [23]. However, $(74.7 \%)$ of participants took less than seven days to come over the withdrawal symptoms, (8\%) took 8-13 days, (17.3) took more than 14 days.

(2) The other major finding of our data suggests that chewing Khat is associated with higher self-reported oral and skin symptoms and signs while chewing compare to after quitting by a significant difference in the means of oral and skin symptoms and signs while chewing Khat and after quitting. Our results in complete agreement with other authors who have reported that oral lesions a high prevalence among populations where use Khat $[9,10,13,24]$. The occurrence of more oral complaints while chewing Khat than after quitting chewing in the current research might be due to a combination of the various mechanisms through which Khat chewing is supposed to induce adverse oral health conditions. As a result of continuous mechanical irritation and friction against mucosa during the chewing session, various pathological changes in the oral tissues, cheeks, and gums can occur [13, 25-27]. Furthermore, the chemical components can also play a role in predispose these lesions [9]. In vitro [28] and in-vivo [29] pathological changes have also been observed in the impact of Khat on the conditions of human oral tissue in histopathological studies, 
which could be attributed to the effects of Khat chemicals as well as to the mechanical. Another study reported that Traumatic ulcers were the most common ulcerative lesions followed by recurrent aphthous stomatitis $[5,30]$. Since the buccal mucosa gets hypertrophic due to the regular Khat chewing irritation [31], the occurrence of cheek biting is reported to be more frequent in chewer, causing considerable buccal tissue trauma. The correlation between mucosal white lesions (strictly limited to the site of chewing) and Khat chewing has been extensively researched and verified by many previous studies [9, 13, 24]. A research published by Schmidt-Westhausen et al.[10], has also shown a significant correlation between Khat chewing and white lesions in Yemeni female. These lesions exacerbate with increased frequency and duration of Khat chewing [13, 32].

Other oral lesions might also be attributable to xerostomia induced by Khat, which is one of the attributable factors affecting tongue conditions. Frequent and regular Khat chewing has been recorded to cause stomatitis, pain or discomfort at the site of chewing [33]. The high prevalence of temporomandibular joint narrowing and condylar flattening radiographic findings have reported by Astatkie, A., et al. [34] with correlation joint discomfort of mouth opening and joint pain in khat chewers, which tend to be attributed to the mechanical impact of regular khat chewing on the temporomandibular joint. Another mechanism is known to act through the irritating and toxic effects of the chemicals, particularly the tannins, in khat $[13,28]$. Halbach [8], has found that the frequent occurrence of stomatitis among Khat chewers could be correlated to astringent tannins.

The toxic effects of pesticides added to the Khat plant in the production process are another mechanism by which Khat could have adverse impact on oral health condition. A previous research has reported that people who chew Khat raised without pesticides have fewer chronic medical issues than those who chew Khat raised with pesticides [33]. Since pesticides could infiltrate the Khat tissues, the chemicals may not be removed by cleaning the leaves before chewing, and thus 
continue to cause an insult to oral health (and general health condition) [33]. Nevertheless, the fact that in the current study, more oral symptoms and signs were observed while chewing may suggest that more oral health care is required. Nevertheless, oral diseases are one of the most costly conditions to treat globally [34]. In developing countries, [34] oral health services would be not only unavailable but also unaffordable. Consequently, lessening or avoiding the exposure to the risk factors have been the most probable option.

By comparing the same group while chewing and after quitting, we found the frequency of skin symptoms and signs while chewing Khat has was more than after quitting. In the current study, the skin symptoms and signs including skin rash (1.9\%), feeling itchy (2.9\%), dry skin rough skin texture $(5.5 \%)$, peeling skin $(3.6 \%)$, abscess $(2.8 \%)$, dark velvety skin patches or spot $(2.7 \%)$, hyperhidrosis $(7.4 \%)$, foul body order $(3.7 \%)$, cold sore oral herpes $(2.9 \%)$, purpura( $2.0 \%)$, noticeable loss of glowing complexing of the face with dark circles or facial fine line $(10.4 \%)$.

Liu et al. [16] reported that pharmaceutically used, methamphetamine use resulted in the manifestation of hyperhidrosis, foul body odor, dry skin (xerosis), lipodystrophy, premature aging, infections secondary to formication, and acne excoriate.

The blood vessels are constricted by Meth which leads to a decrease in the blood flow to the skin, small red spots, or pimples [35]. Ravenel, M.C., et al [17] also reported methamphetamine use manifestations were including poor oral hygiene, dental caries, xerostomia, and bruxism contribute to severe dental decay and loss (mouth meth). As the amphetamine-like sympathomimetic amine is one of the most active ingredients of Khat [2]. In agreement with previous studies, the author reported that long-term use of methamphetamine can lead to a distinctive changes in the physical appearance, producing an aging effect. These changes usually due to malnutrition, severe dental decay, weight loss, and poor hygiene. Chronic users of methamphetamine often show skin-picking 
behaviours and itching, which can cause abscesses and ulcers [35]. The pharmaceutical compound studied in these researches is one of the most active ingredients (amphetamine-like sympathomimetic amine) found in Khat. This could be an explanation for the skin lesion associated with Khat chewers.

Many studies reported the relation between Khat and oral lesion but this is the first study to report the relation between Khat and skin symptoms and signs.

We are aware that several limitations were associated with our cross-sectional study. This study was only a self-reported questionnaire where questions cannot probe or explained. Even though the questionnaire was translated into Arabic, and medical terms were explained in Yemeni slang to avoid vague word bias. As well, a pilot study was done. Other various biases may affect the result as participants' feelings at the time they filled out the questionnaire or guessing our hypothesis in this study and trying to confirm. In addition, the data while chewing Khat was retrospective natural data since participants are ex-chewers now, which may lead to recall bias in our study. More broadly, this is a questionnaire survey study; therefore, the result is not enough. This emphasizes the need for further epidemiological and experimental investigations to assess the possible correlation between Khat and skin lesions.

\section{Conclusions}

The occurrence of oral mucosal and skin symptoms and signs for Yemeni abusers is highly frequent while chewing Khat compares to after quitting chewing. Consequently, preventing or minimizing the exposure to the risk factors seems the more practical option. As well as Khat chewing cessation, programs have the potential to improve oral and skin health. 


\section{Abbreviations}

SD; Standard deviation; M: Mean; P: Probability Value; SPSS: Statistical Package for Social Science; USA: United State of America; WHO: World Health Organization

\section{ACKNOWLEDGMENTS}

The author would like to thank the Yemeni participants in Chain for their participation in this study. Thanks are extended to Dr. Eman Ahmed Alawamy, Central South University, Hunan, for her help in statistical analysis. Special thanks is also extended to Eng. Emad Mohsen, Shandong University of Technology, Shandong for his help in Design online website for the Questioner. Thanks are extended to Dr. Nashwa A. Albarmaqi, Taiz medical University, Taiz for reviewing this paper and offering extremely valuable comments.

\section{Authors' contributions}

RAA conducted the study and wrote all drafts supported by YQK, YYL, and NSG. All authors participated in developing the overall study design. All authors were involved in drafting and finalizing the paper. All authors read and approved the final manuscript.

\section{Funding}

This study was supported in part by the National Natural Science Foundation of China [grant number 81860553and 81860553], the Project for Innovation Team of Department of Science and Technology of Yunnan Province, China [grant number 2018HC005], the "Ten-thousand Talents Program” of Yunnan Province, China, the Medical Leadership Foundation of Health and Family Planning Commission of Yunnan Province, China [grant number L-201613], and the Joint Special Fund of Science and Technology Department of Yunnan Province - Kunming Medical University [grant number 2017FE467(-005)]. 


\section{Availability of data and materials}

The datasets used and/or analyzed during the current study are available from the corresponding author on reasonable request.

\section{Declarations}

\section{Ethics approval and consent to participate}

Ethical clearance and permission was obtained from Kunming first affiliated Hospital and Kunming Medical University. The data collection was carried out using an online questionnaire which was pretested. Potential participants were invited through a text message on WeChat Yemeni Groups, which connected them to a survey page. Data was collected anonymously, with no information that could be used to identify the participants.

\section{Consent for publication}

Not applicable.

\section{Competing interests}

The authors declare that they have no competing interests.

\section{Author details}

Rowida A. Albarmaqi MD ${ }^{1,2}$, Yi-Qun Kuang $\mathrm{PhD}^{2,3}$, Yu-Ye Li $\mathrm{PhD}^{1,2}$, Noha Saleh Gholais $\mathrm{MD}^{4}$

${ }^{1}$ Department of Dermatology and Venereology, First Affiliated Hospital of Kunming Medical University, Kunming, Yunnan, China

${ }^{2}$ NHC Key Laboratory of Drug Addiction Medicine, First Affiliated Hospital of Kunming Medical University, Kunming Medical University, Kunming, Yunnan, China

${ }^{3}$ Scientific Research Laboratory Center, First Affiliated Hospital of Kunming Medical University, Kunming, Yunnan, China 


\section{REFERENCES}

[1] Ageely, H.M., Prevalence of Khat chewing in college and secondary (high) school students of Jazan region, Saudi Arabia. Harm Reduct J, 2009. 6: p. 11.

[2] Kalix, P., Cathinone, a natural amphetamine. Pharmacol Toxicol, 1992. 70(2): p. 77-86.

[3] Nakajima, M., et al., Gender differences in patterns and correlates of khat and tobacco use. Nicotine Tob Res, 2013. 15(6): p. 1130-5.

[4] Al-Kholani, A.I., Influence of Khat Chewing on Periodontal Tissues and Oral Hygiene Status among Yemenis. Dent Res J (Isfahan), 2010. 7(1): p. 1-6.

[5] Al-Maweri, S.A., N.A. Alaizari, and G.A. Al-Sufyani, Oral mucosal lesions and their association with tobacco use and qat chewing among Yemeni dental patients. J Clin Exp Dent, 2014. 6(5): p. e460-6.

[6] Al-Maweri, S.A. and G. Al-Sufyani, OP144: Prevalence of oral cancer, potentially malignant lesions and oral habits among patients visiting dental school, Sana'a University. Oral Oncology, 2013. 49: p. S59.

[7] Dhaifullah, E., et al., Periodontal Health Condition and Associated Factors among University Students, Yemen. J Clin Diagn Res, 2015. 9(12): p. Zc30-3.

[8] Halbach, H., Medical aspects of the chewing of khat leaves. Bull World Health Organ, 1972. 47(1): p. 21-9.

[9] Ali, A.A., et al., A study of 342 oral keratotic white lesions induced by qat chewing among 2500 Yemeni. J Oral Pathol Med, 2004. 33(6): p. 368-72.

[10] Schmidt-Westhausen, A.M., J. Al Sanabani, and A.K. Al-Sharabi, Prevalence of oral white lesions due to qat chewing among women in Yemen. Oral Dis, 2014. 20(7): p. 675-81.

[11] Al-hebshi, N. and M. Alakhali, Experimental gingivitis in male khat (Catha edulis) chewers. Journal of the International Academy of Periodontology, 2010. 12: p. 56-62.

[12] Yarom, N., et al., Oral manifestations of habitual khat chewing: a case-control study. Oral Surg Oral Med Oral Pathol Oral Radiol Endod, 2010. 109(6): p. e60-6.

[13] Gorsky, M., et al., Oral white lesions associated with chewing khat. Tob Induc Dis, 2004. 2(3): p. 145-50.

[14] Al-Maweri, S., S. Warnakulasuriya, and A. Samran, Khat (Catha edulis) and its oral health effects An updated review. Journal of Investigative and Clinical Dentistry, 2017. 9.

[15] Hill, C.M. and A. Gibson, The oral and dental effects of q'at chewing. Oral Surg Oral Med Oral Pathol, 1987. 63(4): p. 433-6.

[16] Liu, S.W., M.H. Lien, and N.A. Fenske, The effects of alcohol and drug abuse on the skin. Clin Dermatol, 2010. 28(4): p. 391-9.

[17] Ravenel, M.C., et al., Methamphetamine abuse and oral health: a pilot study of "meth mouth". Quintessence Int, 2012. 43(3): p. 229-37. 
[18] Locker, D. and Y. Miller, Evaluation of subjective oral health status indicators. J Public Health Dent, 1994. 54(3): p. 167-76.

[19] Cox, G. and H. Rampes, Adverse effects of khat: a review. Advances in Psychiatric Treatment, 2003. 9(6): p. 456-463.

[20] Kalix, P. and O. Braenden, Pharmacological aspects of the chewing of khat leaves. Pharmacol Rev, 1985. 37(2): p. 149-64.

[21] Nutt, D., et al., Development of a rational scale to assess the harm of drugs of potential misuse. The Lancet, 2007. 369(9566): p. 1047-1053.

[22] Abebe, W., Khat and synthetic cathinones: Emerging drugs of abuse with dental implications. Oral Surgery, Oral Medicine, Oral Pathology and Oral Radiology, 2018. 125(2): p. 140-146.

[23] Balint, E.E., G. Falkay, and G.A. Balint, Khat - a controversial plant. Wiener klinische Wochenschrift, 2009. 121(19): p. 604.

[24] Halboub, E., E. Dhaifullah, and M. Abdulhuq, Khat chewing and smoking effect on oral mucosa: a clinical study. Acta Medica (Hradec Kralove), 2009. 52(4): p. 155-8.

[25] Ali, A.A., Qat habit in Yemen society: a causative factor for oral periodontal diseases. Int J Environ Res Public Health, 2007. 4(3): p. 243-7.

[26] Astatkie, A., M. Demissie, and Y. Berhane, The association of khat (Catha edulis) chewing and orodental health: A systematic review and meta-analysis. S Afr Med J, 2014. 104(11): p. 773-779.

[27] Al-Sharabi, A.K., et al., Qat chewing as an independent risk factor for periodontitis: a cross-sectional study. Int J Dent, 2013. 2013: p. 317640.

[28] Lukandu, O.M., et al., Khat alters the phenotype of in vitro-reconstructed human oral mucosa. J Dent Res, 2010. 89(3): p. 270-5.

[29] Ali, A.A., A.K. Al-Sharabi, and J.M. Aguirre, Histopathological changes in oral mucosa due to takhzeen al-qat: a study of 70 biopsies. J Oral Pathol Med, 2006. 35(2): p. 81-5.

[30] Ali, M., B. Joseph, and D. Sundaram, Prevalence of oral mucosal lesions in patients of the Kuwait University Dental Center. Saudi Dent J, 2013. 25(3): p. 111-8.

[31] Astatkie, A., et al., Oral symptoms significantly higher among long-term khat (Catha edulis) users in Ethiopia. Epidemiol Health, 2015. 37: p. e2015009.

[32] Lukandu, O.M., L.S. Koech, and P.N. Kiarie, Oral Lesions Induced by Chronic Khat Use Consist Essentially of Thickened Hyperkeratinized Epithelium. Int J Dent, 2015. 2015: p. 104812.

[33] Astatkie, A., et al., Oral symptoms significantly higher among long-term khat (Catha edulis) users in Ethiopia. Epidemiology and health, 2015. 37: p. e2015009-e2015009.

[34] Petersen, P.E., Challenges to improvement of oral health in the 21 st century--the approach of the WHO Global Oral Health Programme. Int Dent J, 2004. 54(6 Suppl 1): p. 329-43.

[35] Hennings, C. and J. Miller, Illicit drugs: What dermatologists need to know. journal of the american academy of dermatology, 2013. 69(1): p. 135-142. 
Fig. 1. Withdrawal symptoms after quitting chewing Khat

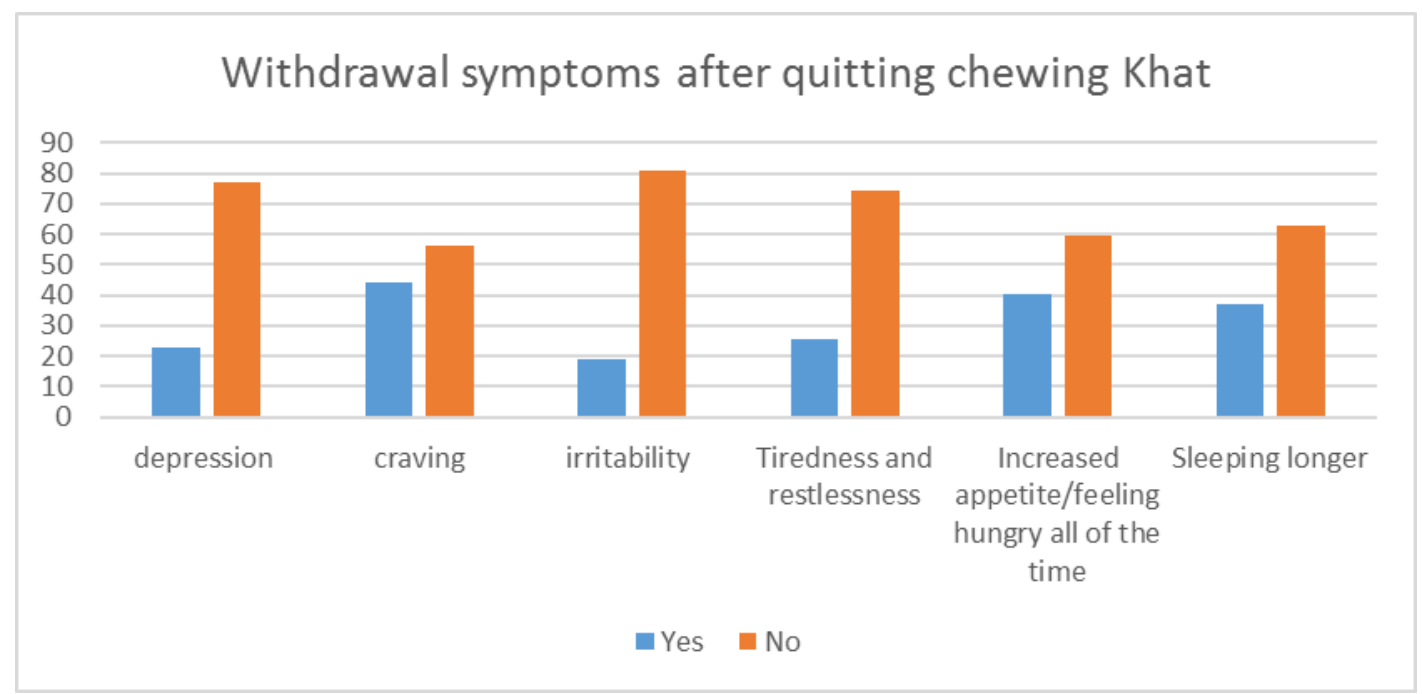


Table 1. Socio-demographic characteristic of the study participants

\begin{tabular}{|c|c|c|}
\hline Characteristics & $\mathbf{N}$ & $\%$ \\
\hline \multicolumn{3}{|l|}{ Gender } \\
\hline male & 255 & 85.0 \\
\hline Female & 45 & 15.0 \\
\hline \multicolumn{3}{|l|}{ Age } \\
\hline $15-24$ & 94 & 31.3 \\
\hline $25-34$ & 175 & 58.3 \\
\hline $35-44$ & 28 & 9.3 \\
\hline$\geq 45$ & 3 & 1.0 \\
\hline \multicolumn{3}{|l|}{ Education } \\
\hline Able to read and write & 1 & 0.3 \\
\hline Primary & 4 & 1.3 \\
\hline Secondary & 23 & 7.7 \\
\hline bachelor & 119 & 39.7 \\
\hline Postgraduate & 153 & 51 \\
\hline \multicolumn{3}{|l|}{ Employment } \\
\hline employed & 22 & 7.3 \\
\hline Unemployed & 7 & 2.3 \\
\hline Merchant & 24 & 8.0 \\
\hline Student & 218 & 72.7 \\
\hline Others & 29 & 9.7 \\
\hline \multicolumn{3}{|c|}{ length of stay in china (year) } \\
\hline$>1$ & 48 & 16.0 \\
\hline $2-4$ & 65 & 21.7 \\
\hline $5-7$ & 130 & 43.3 \\
\hline$\geq 8$ & 57 & 19.0 \\
\hline \multicolumn{3}{|l|}{ Smoke cigarettes } \\
\hline Yes & 83 & 27.7 \\
\hline No & 217 & 72.3 \\
\hline \multicolumn{3}{|l|}{ Smoke water pipe } \\
\hline Yes & 119 & 39.7 \\
\hline No & 181 & 60.3 \\
\hline \multicolumn{3}{|l|}{ Systemic disease } \\
\hline yes & 6 & 2.0 \\
\hline No & 294 & 98.0 \\
\hline \multicolumn{3}{|c|}{ Member of family who chews Khat } \\
\hline yes & 273 & 91.0 \\
\hline no & 27 & 9.0 \\
\hline
\end{tabular}


Table 2. Chewing Khat statues

\begin{tabular}{lcc}
\hline Chewing Khat duration by years & Frequency & Ratio \\
$\leq 3$ & 121 & 40.3 \\
$4-7$ & 100 & 33.3 \\
$8-11$ & 45 & 15.0 \\
$12-15$ & 16 & 5.3 \\
$\geq 16$ & 18 & 6.0 \\
Session duration hours per day & & \\
$1-3$ & 108 & 36.0 \\
$4-6$ & 123 & 41.0 \\
$7-9$ & 50 & 16.7 \\
$\geq 10$ & 19 & 6.3 \\
Amount of chewed Khat bundles per session & & \\
Quarter bundle & 103 & 34.3 \\
Half of bundle & 60 & 20.0 \\
One bundle & 101 & 33.7 \\
more than one bundle & 36 & 12.0 \\
\hline
\end{tabular}

Table 3. Duration of withdrawal symptoms

\begin{tabular}{ccc}
\hline Duration & Frequency & Percent \\
\hline$\leq 7$ days & 224 & 74.7 \\
$8-13$ days & 24 & 8 \\
$\geq 14$ day & 52 & 17.3 \\
Total & 300 & 100.0 \\
\hline
\end{tabular}


Table 4. Oral symptoms and signs while chewing after quitting among ex-chewers participants in china $(n=300)$

\begin{tabular}{lcccc}
\hline Oral symptoms and signs & While chewing Khat & & After quitting chewing Khat & \\
& frequency & ratio & frequency & ratio \\
\cline { 2 - 5 } & 83 & $10.7 \%$ & 26 & $2.6 \%$ \\
Difficulty chewing & 91 & $11.7 \%$ & 33 & $3.3 \%$ \\
food(pain ) & 94 & $12.1 \%$ & 28 & $2.8 \%$ \\
Mouth Sores /irritation & 61 & $7.9 \%$ & 30 & $3.0 \%$ \\
Mouth Angular Fissure & 67 & $8.6 \%$ & 48 & $4.7 \%$ \\
Mouth white spots & 80 & $10.3 \%$ & 41 & $4.0 \%$ \\
Oral malodor & 123 & $15.8 \%$ & 34 & $3.3 \%$ \\
Gum bleeding & 68 & $8.8 \%$ & 23 & $2.3 \%$ \\
Change color of the & 62 & $8.0 \%$ & 21 & $2.1 \%$ \\
tongue & & & 17 & $1.7 \%$ \\
Tongue fissure & 48 & $6.2 \%$ & & \\
tongue bumps or lump oral & & & & \\
Raised bumps that are red & & & &
\end{tabular}

Table 5. Skin symptoms and signs while chewing after quitting among participation ex-chewers in china $(n=300)$

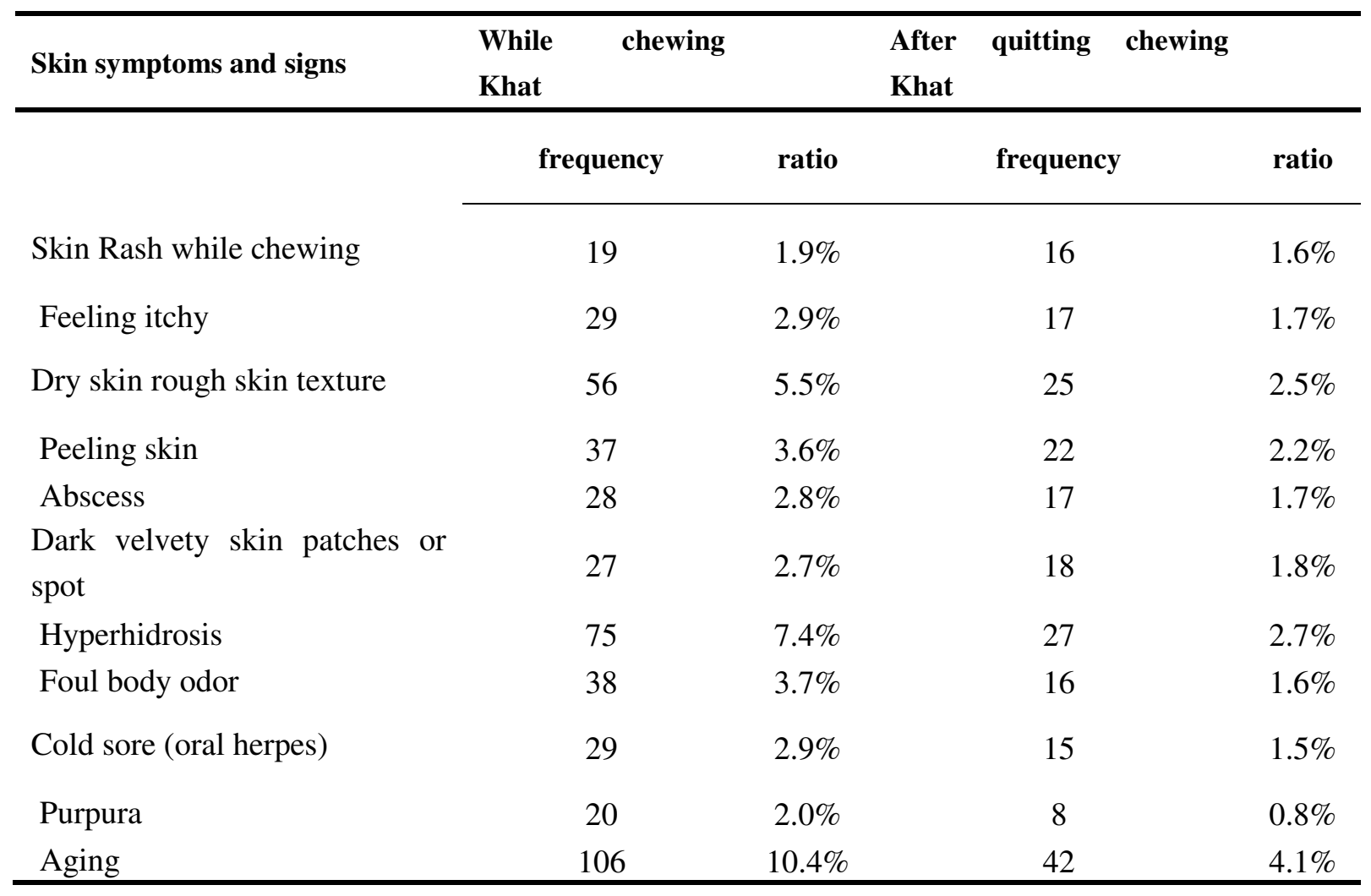




\begin{tabular}{lllll}
\hline Herpes zoster while chewing & 17 & $1.7 \%$ & 10 & $1.0 \%$ \\
\hline
\end{tabular}

Table 6. Paired t-test analysis for the difference in means between while chewing and after quitting for skin and oral

\begin{tabular}{llccccc}
\hline & & Mean & $\mathbf{N}$ & Std. Deviation & t-test & p-value \\
\cline { 3 - 7 } Pair1 & Oral while chewing & 0.26 & 300 & 0.22 & 12.00 & .000 \\
& Oral after quitting & 0.10 & 300 & 0.27 & & \\
Pair2 & Skin while chewing & 0.13 & 300 & 0.28 & 9.41 & \\
& Skin after quitting & 0.06 & 300 & 0.21 & & .000 \\
\hline
\end{tabular}

